Zhang. Y. X., Li, J. S., \& Li, Y. (2012). Design features and academic emotions in educational games. Journal of Educational Technology Development and Exchange, 5(1), 29-44.

\title{
Design Features and Academic Emotions in Educational Games
}

\author{
Yue-Xiang Zhang \\ Wuxi No.1 Senior High School \\ Jian-Sheng Li \\ Yi Li \\ Nanjing Normal University
}

\begin{abstract}
The purpose of this study is to investigate how the design features affect the players' academic emotions in educational games. As a sample, 36 players were recruited to evaluate six electronic games on training players' abilities to use the games. The researchers averaged their evaluation scores and considered related scales of three games concerning "Ballance", "Rescue" and "Gates of Logic." Forty participants (19 female and 21 male) were tested on academic emotions and on the Learners' Psychological Pleasure Scale. Results of this study reveal significant differences in educational games design features and academic emotions, such as a positive correlation between control and positive-high arousal emotions/ concentration and positive-high arousal emotions; a negative correlation between concentration and negativelow arousal emotions/challenge; and a negative-high arousal emotions/immersion and negative emotions. Therefore, these results may contribute to the emotional design embedded in educational games.
\end{abstract}

Keywords: educational games, educational games design features, academic emotions

\section{Introduction}

Educational games have no unified academic definition, that are also known as learning games, edutainment, serious games, etc. Scholars have generally agreed that educational games are the integration of education and computer games, and they apply game-based learning environment to education such as "Edutainment." This is a hybrid genre that relies heavily on visual material, on narrative or game-like formats, and on more informal, less didactic styles of address. The purpose of edutainment is to attract and hold the attention of the learners by engaging their emotions through a computer monitor full of vividly colored animations (Buckingham \& Scanlon, 2000). "Educational games" have been designed in order to combine game dynamics with educational content (EgenfeldtNielsen, 2005). "Serious games" are not considered a game genre, but a category of games with different purposes. This category includes educational games and advergames, political games, or evangelical games (Diener, 2006). Because of the advantages of the 
sensory and contextual design, the educational games can stimulate students' motivation and interest in learning more efficiently (Dede et al, 2002; Jong et al, 2006), and increase kids critical thinking, cooperation, and problemsolving skills (Bruckman, 1998; Prensky, 2000). Playing games can also teach students more knowledge and provide learning that is deep, sustained and transferable to the real world (Lee et al, 2006).

The value of educational games has been widely accepted, but excellent educational games are rare. One of the most important reasons may be the insufficiencies of emotional elements in educational game design. In recent years, the emotional elements have been recognized and discussed among game researchers. Ravaja and Saari (2006) suggested that the nature of the opponent (computer, friend, or stranger) influences emotional responses when playing video games. Customization of game avatars can affect both subjective feelings of presence and psychophysiological indicators of emotion during gameplay, which may make the gameplay experience more enjoyable (Bailey et al, 2009). In addition, interactivity within games influences the overall emotion management effect in that only highly interactive video gamers can simultaneously increase positive affects and decrease negative affects (Chen, 2010). Furthermore, some researchers thought the emotional addiction is one of the most important factors of computer game addiction, especially for RPG (Roleplaying game). Even so, the emotional reactions are not introduced by the designers on purpose (Weinstein, 2010; Zhou \& Zhang, 2010). Therefore, it is necessary to consider what types of design features in educational games can influence students' emotions as way to rouse students' positive emotional experience. Under this circumstance, we focus on the educational games design features and emotions in our research. To make terminology clear, the players' emotions are referred to academic emotions in this research.

\subsection{Educational Games Design Features}

Experiential Gaming Model (Kiili, 2005) showed that we should consider three kinds of factors when we design educational games. First, from an educational perspective, the theoretical basis that can be used in designing educational games are Experience Learning Theory, Constructivism Learning Theory, and Problem-based Learning. This combined game-based learning theory is very important because the field of educational technology has lacked theoretical basis in the past. Second, a psychological perspective or a model that aims to support the design of flow in educational games is important. The flow antecedents to be considered in educational game design are challenges matched to player's skill level, clear goals, unambiguous feedback, sense of control, playability, gamefulness, focused attention, and a frame story used to situate the problems of the game. Third, a game design perspective in which the only goal of the game is to let players to feel pleasure needs to be integrated. The degree of pleasure is generally measured through "game interfaces," "game mechanism," "rules of the game," and "the story of the game." Sweetser and Wyeth (2005) have drawn together the various heuristics into a concise model of enjoyment in games that is structured by flow. Their model, GameFlow, consists of eight elements: concentration, challenge, skills, control, clear goals, feedback, immersion, and social interaction. Su Rongzhang (2007) found that educational games' design features include concentration, clear goals, feedback, challenge, control, immersion, and social interaction, and developed "Learners' Psychological Pleasure Scale." On the other hand, a lot of studies have showed that the 
emotions could influence students' learning (Goleman, 1995; John-Steiner, 2000).

\subsection{Academic Emotions}

Academic emotions describe students' emotional experiences associated with learning (Pekrun et al, 2002). Over the past decades, academic emotions have been taken a consistent attention in the field of education. Researchers have increasingly held high interest in students' emotional experience related to learning. Previous research on the academic emotions had typically used dichotomous conceptions of emotions (i.e., positive affect vs. negative affect) and a few kinds of discrete achievement emotions. Dichotomous conceptions disregard important qualitative differences between discrete emotions, which are probably one reason why findings of the extant research lack consistency (Pekrun et al, 2006). Pekrun, Gort, and Titz (2002) took arousal into account, and classified the academic emotions into four dimensions: positive-high arousal, positive-low arousal, negative-high arousal, and negative-low arousal emotions. In this study, we used four dimensions of academic emotions, which classified the discrete emotions into four dimensions. This way we could take important qualitative differences between emotions into account and explore all kinds of emotions instead of a few discrete emotions.

A lot of research about academic emotions in traditional teaching situation and E-learning has been made. Nummenmaa and Nummenmaa (2008) examined how academic emotions experienced while using a WBLE. Students' interest towards the course topic and interest towards web-based learning are associated with collaborative visible and non-collaborative invisible activities and "lurking" in the WBLE. The research showed that the fluctuation of academic emotions was positively associated with both visible collaborative and invisible noncollaborative activities in the WBLE. Further, interest towards the web-based learning was positively associated with invisible activity. The results also demonstrated that students not actively participating in the collaborative activities (i.e., lurkers) have more negative emotional experiences during the courses than other students. However, little research about academic emotions has been performed in educational games, which is a new type of educational means.

\section{Research Goals}

The purpose of this study is to explore the relations between the educational games' design features and the students' academic emotions. We tried to consider how and what types of educational games' design features would most influence participants' academic emotions. Based on the theoretical background presented above, we articulated a theoretical model of the relationships between educational games' design features and academic emotions that uses more differentiated conceptions of both educational games design features and emotions by linking the six design elements ( $\mathrm{Su}, 2007)$ to students' four dimensions of academic emotions. We classified the discrete emotions into four dimensions in this study (refer to Table 1) so that we could explore all kinds of emotions instead of a few discrete emotions. Meanwhile, according to the players' channels, we chose three types of educational games for our experimental environment. Figure 1 displays our research structure. We assumed that different kinds of educational games' design features have different influence on students' emotional experiences in the three education games. Specific hypotheses are as follows: 
Hypothesis 1. The educational games' design features of Learners' Psychological Pleasure Scale positively predict positive emotions in varying degrees.
Hypothesis 2. The educational games' design features of Learners' Psychological Pleasure Scale negatively predict negative emotions in varying degrees.

Table 1. Four Dimensions of Academic Emotions (Dong and Yu, 2007)

\begin{tabular}{ll}
\hline Positive-high Arousal & pride, enjoyment, hope \\
Positive-low Arousal & satisfied, calm, relaxation \\
Negative-high Arousal & anxiety, shame, anger \\
Negative-low Arousal & boredom, helplessness, dejected, tired \\
\hline
\end{tabular}

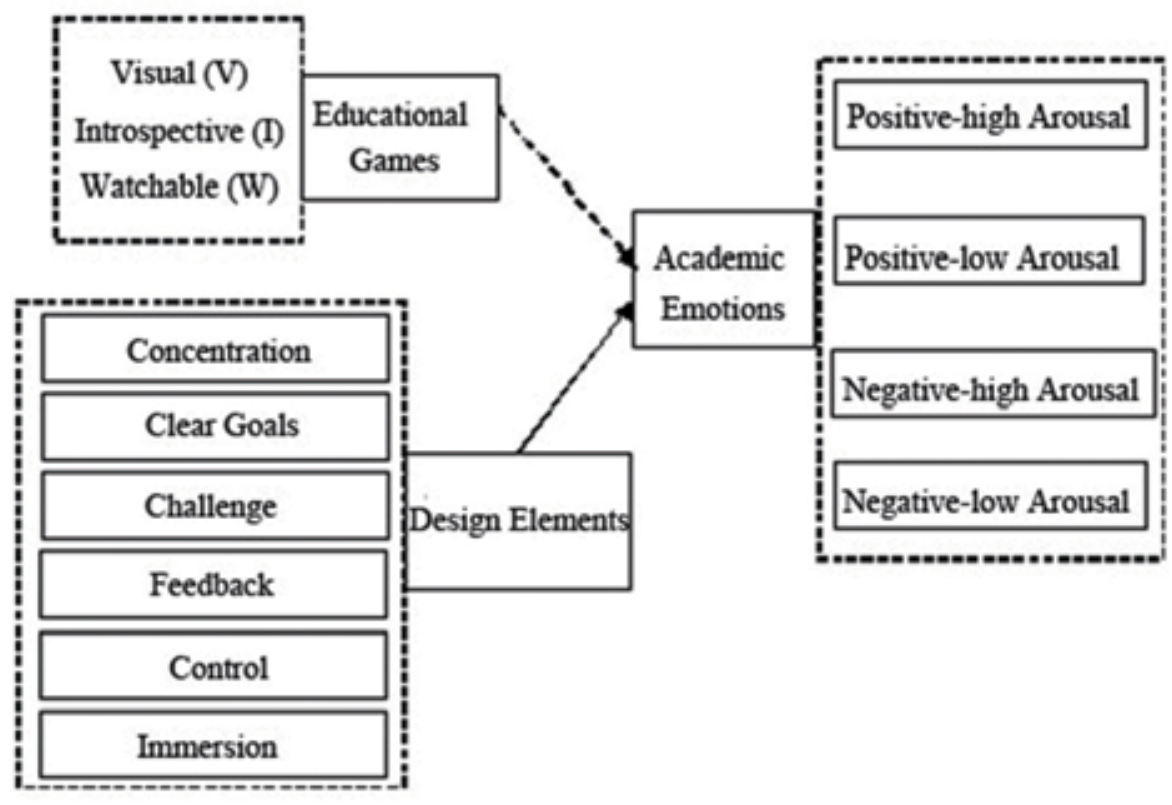

Figure 1. Research structure

\section{Method}

Our research adopted an experimental method. Gathering the data of participants' academic emotions and educational games' design features when the participants played the three educational games was collected. Information on educational games design features was gathered using Su Rongzhang's (2007) Learners' Psychological Pleasure Scale, and 
using the biofeedback instrument (Spirit16) and Chinese Version of Abbreviated PAD Emotion Scales to record the participants' academic emotions.

\subsection{Educational Games}

Our research chose electronic games according to "Grading and Classification of Electronic Games in Educational Perspective" (Wang, 2010). This evaluation system divides electronic games into eight types: Linguistic (L), Musical (M), Logical (R), Visual (V), Kinesthetic (P), Social (S), Introspective (I), and Watchable (W). Thirty-six graduate students from Nanjing Normal University who are interested in playing educational games were chosen randomly to evaluate six electronic educational games that trained each of the eight types of players' abilities. The researchers averaged their evaluation scores and compared this to the corresponding rating scale that we determined as classifications of electronic games in educational perspective. Thus, we chose three games-"Ballance," "Rescue," and "Gates of Logic"- that had unique and definite educational functions. "Ballance" is the debut of the German game studio CYPARADE, which is a personal game with 12 levels. "Rescue" is a role-playing game, which is designed and developed by undergraduates of Zhejiang Normal University. It is designed for "Learning to Live" proposed by UNESCO. Players can learn a lot of knowledge about safety and first aid in the process of adventure. "Gates of Logic" is a personal game, and it is designed according to and gate, or gate, not gate. Table 2 presents three games' average of eight aspects in educational perspective. The result presents that "Ballance" is a "visual" electronic game, "Rescue" is an "introspective" electronic game, and "Gates of Logic" is a "watchable" electronic game.

Table 2. Three Games' Average of Eight Aspects in Educational Perspective

\begin{tabular}{ccccccccc}
$\begin{array}{c}\text { Type } \\
\text { Games }\end{array}$ & $\mathrm{L}$ & $\mathrm{M}$ & $\mathrm{R}$ & $\mathrm{V}$ & $\mathrm{P}$ & $\mathrm{S}$ & $\mathrm{I}$ & $\mathrm{W}$ \\
\hline Ballance & $5.5(\mathrm{C})$ & $23.5(\mathrm{C})$ & $33.0(\mathrm{C})$ & $82.25(\mathrm{~A})$ & $34.0(\mathrm{C})$ & $15.5(\mathrm{C})$ & $22.35(\mathrm{C})$ & $23.5(\mathrm{C})$ \\
Rescue & $23.5(\mathrm{C})$ & $23.0(\mathrm{C})$ & $31.5(\mathrm{C})$ & $43.3(\mathrm{~B})$ & $18.5(\mathrm{C})$ & $45.05(\mathrm{~B})$ & $72.91(\mathrm{~A})$ & $7.85(\mathrm{C})$ \\
$\begin{array}{c}\text { Gates of } \\
\text { Logic }\end{array}$ & $18.5(\mathrm{C})$ & $23.5(\mathrm{C})$ & $42.0(\mathrm{~B})$ & $33.0(\mathrm{C})$ & $37.0(\mathrm{C})$ & $34.5(\mathrm{C})$ & $25.5(\mathrm{C})$ & $78.9(\mathrm{~A})$ \\
\hline
\end{tabular}

\subsection{Participants}

Three hundred undergraduates from Nanjing Normal University, Hohai University, and Nanjing Xiaozhuang College completed the "Basic Information Questionnaire" before the experiment that asked information such as gender, age, experience, and preference for the games. We also recorded their phone numbers so that we could contact them for the followup experiments. Forty (19 female and 21 male) participants were selected who did not play the three games before and they all had a similar preference for the games. Thus, we could exclude the interference of the players' experience and preferences. 


\subsection{Measures}

\subsubsection{Academic Emotions}

The emotional states of each player in the games were assessed with combination of a biofeedback instrument (Spirit-16) and the Chinese Version of Abbreviated PAD Emotion Scales.

Biofeedback instrument (Spirit-16) can record people's biofeedback during playing games quickly, including electroencephalogram (EEG), galvanic skin response (GSR), temperature (Temp), blood volume pulse (BVP), Electro-Oculogram (EOG), and heart rate variability (HRV), which can be used to measure human emotion. GSR is one of the most commonly used indicators to measure the emotional response. GSR reflects secretory response of sweat glands, and the change of emotional arousal leads to significant variation of the GSR. Generally, the movement of galvanic skin has a certain resistance parameters, but when it is subjected to external fresh stimulus or emotional stimulus, galvanic skin will be enhanced and the resistance decreases. Hence, GSR is considered as one of the objective index for emotion measure (Cai, 2010). Our research chose GSR to reflect participants' emotional states.

The PAD Emotion Scales was build upon the PAD Emotional State Model, which is proposed by Mehrabian and Russell (1974). It was an elaborate tool for measuring emotions developed by Dr. Mehrabian of University of California, Los Angeles (1995). There are three nearly independent dimensions that are used to describe and measure emotional states in the PAD Emotional State Model: pleasure-displeasure $(\mathrm{P})$, which distinguishes the positive and negative quality of individual emotional states; arousal-nonarousal (A), which refers to a combination of physical activity and mental alertness; and dominancesubmissiveness (D), which is defined in terms of control of the scenarios and other person versus lack of control. Specific emotional states can be visualized as points on a threedimensional PAD emotion space (Mehrabian, 1995). Later, researchers further proposed abbreviated versions of the PAD Emotion Scales. Our research chose the Chinese Version of Abbreviated PAD Emotion Scales that has been revised by $\mathrm{Li}$ and $\mathrm{Fu}$ (Li et al, 2005).

The Chinese Version of Abbreviated PAD Emotion Scales has 12 items, and each dimension consist of four items. Each item of the PAD Emotion Scales consists of a word pair that is separated by nine spaces. The two words on each line refer to feelings and highlight a special contrast between the two feelings. Participants were required to indicate which end of the scale is heavier or stronger (and by how much) as an accurate description of their feelings by placing a check-mark in one of the nine spaces. Participants responded on a -4 ("feeling A" is much stronger than "feeling B") to 4 ("feeling B" is much stronger than "feeling A") scale, and " 0 " representing that feeling $\mathrm{A}$ is as strong as feeling $\mathrm{B}(\mathrm{Li}$ et al, 2005). Cronbach's $\alpha$ was computed to gauge the inter-item consistencies for P, A, and D (P: $\alpha=0.773$; A: $\alpha=0.563$; D: $\alpha=0.735)$. The detailed results are displayed in Table 3.

\subsubsection{Educational Games Design Features}

Educational games design features were assessed using Su Rongzhang's (2007) Learners' Psychological Pleasure Scale. This scale was developed on the basis of eight factors of the GameFlow Model proposed by Sweetser and Wyeth (2005).

The Learners' Psychological Pleasure Scale contains seven subscales that have between four to seven items for each subscale. Because our experimental environment was 
Table 3. The Inter-item Consistencies for P, A, and D

\begin{tabular}{|c|c|c|c|c|c|c|}
\hline Dimension & Item & $\begin{array}{l}\text { Scale Mean if } \\
\text { Item Deleted }\end{array}$ & $\begin{array}{l}\text { Scale Variance } \\
\text { if Item Deleted }\end{array}$ & $\begin{array}{c}\text { Corrected } \\
\text { Item-Total } \\
\text { Correlation }\end{array}$ & $\begin{array}{l}\text { Cronbach's } \\
\text { Alpha if Item } \\
\text { Deleted }\end{array}$ & $\begin{array}{c}\text { Cronbach's } \\
\text { Alpha }\end{array}$ \\
\hline \multirow[t]{4}{*}{$\mathrm{P}$} & Q1 & 3.4833 & 15.798 & .640 & .684 & .773 \\
\hline & Q4 & 3.4333 & 17.659 & .496 & .760 & \\
\hline & Q10 & 3.9167 & 16.077 & .616 & .697 & \\
\hline & Q7 & 3.8167 & 18.067 & .558 & .729 & \\
\hline \multirow[t]{4}{*}{ A } & Q5 & 1.6083 & 24.392 & .272 & .558 & .563 \\
\hline & Q11 & 1.8250 & 27.137 & .234 & .577 & \\
\hline & Q2 & .4167 & 23.522 & .411 & .440 & \\
\hline & Q8 & 1.3000 & 21.556 & .492 & .367 & \\
\hline \multirow[t]{4}{*}{$\mathrm{D}$} & Q3 & 1.0167 & 24.739 & .596 & .631 & .735 \\
\hline & Q6 & 1.0083 & 33.185 & .340 & .766 & \\
\hline & Q12 & 1.1083 & 28.904 & .516 & .681 & \\
\hline & Q9 & 1.4917 & 22.941 & .669 & .582 & \\
\hline
\end{tabular}

P: pleasure-displeasure; A: arousal-nonarousal; D: dominance-submissiveness

personal games, we removed the subscale of "social interaction." Thus, we used six subscales, which were concentration, clear goals, feedback, challenge, control, and immersion. Participants responded on a 1 (Strongly disagree) to 7 (Strongly agree) scale, and scores were summed to create the six subscales indexes (Concentration: $\alpha=0.700$; Clear goals: $\alpha=0.833$; Feedback: $\alpha=$ 0.852; Challenge: $\alpha=0.653$; Control: $\alpha=0.829$; Immersion: $\alpha=0.929$; and the Learners' Psychological Pleasure Scale: $\alpha=0.904$ ). Finally, we also tested the overall pleasure gained from each game.

\subsection{Procedure}

Participants completed the measures in two different sessions. They completed the Basic Information Questionnaire (300 participants) in their classroom. The academic emotions and the educational games design features of Learners' Psychological Pleasure Scale measures were administered approximately a week after completion of the basic information measure (40 participants) in a Biofeedback laboratory. Every participant completed the academic emotion measure alone. The experiment was conducted on the premise that participants were voluntary.

At the beginning of the experiment, the assistant introduced the experiment to each participant. After three minutes, we recorded the GSR data for basic galvanic skin. Then, the participants began to play the games without any tips. They responded to the Chinese Version of Abbreviated PAD Emotion Scales and Learners' Psychological Pleasure Scale after the end of each game, and then relaxed for five minutes for next game. Each game is 15 minutes in length. The biofeedback instrument recorded their galvanic skin throughout the 
playing proceedings. Thus, we computed the changes of their GSR. The assistant then later uploaded all data after the experiment.

\section{Results}

\subsection{Descriptive Statistics}

Prior to the primary analyses, the descriptive statistics for each of the variables in the study was conducted. Table 4 displays the descriptive statistics for the Learners' Psychological Pleasure Scale.

The academic emotions of each player in the games were assessed with combination of GSR and the Chinese Version of Abbreviated PAD Emotion Scales. Table 5 displays the descriptive statistics for GSR and PAD.

Table 4. Descriptive Statistics for Learners' Psychological Pleasure Scale

\begin{tabular}{lccccccc}
\hline & & \multicolumn{2}{c}{ Game A Rescue } & \multicolumn{2}{c}{ Game B Gates of Logic } & \multicolumn{2}{c}{ Game C Ballance } \\
\cline { 3 - 8 } & $\mathrm{N}$ & Mean & Std. Deviation & Mean & Std. Deviation & Mean & Std. Deviation \\
\hline Concentration & 40 & 28.4146 & 5.23438 & 27.9024 & 6.42964 & 30.6341 & 5.65578 \\
Clear goals & 40 & 20.5610 & 7.43656 & 14.2195 & 6.33448 & 12.8293 & 6.49193 \\
Feedback & 40 & 27.7073 & 4.62193 & 22.4390 & 6.52322 & 25.0000 & 6.50000 \\
Challenge & 40 & 28.5366 & 6.50038 & 26.7317 & 6.35620 & 27.9024 & 5.82153 \\
Control & 40 & 30.7073 & 8.03817 & 29.6341 & 9.42007 & 35.1463 & 8.47809 \\
Immersion & 40 & 35.1707 & 8.68879 & 32.1707 & 10.88784 & 38.9024 & 8.93813 \\
\hline
\end{tabular}

Table 5. Descriptive Statistics for GSR and PAD

\begin{tabular}{crrrrrrc}
\hline & & \multicolumn{2}{c}{ Game A Rescue } & \multicolumn{2}{c}{ Game B Gates of Logic } & \multicolumn{2}{c}{ Game C Ballance } \\
\cline { 3 - 7 } & $\mathrm{N}$ & Mean & Std. Deviation & Mean & Std. Deviation & Mean & Std. Deviation \\
\hline GSR & 40 & 2.0221 & 2.44131 & 3.4089 & 3.80271 & 4.4432 & 4.84074 \\
$\mathrm{P}$ & 40 & .9936 & .78742 & .8205 & 1.64532 & 1.8013 & 1.23168 \\
$\mathrm{~A}$ & 40 & -.6603 & 1.11875 & .5641 & 1.30500 & 1.3654 & 1.48329 \\
$\mathrm{D}$ & 40 & -.6346 & 1.06969 & .1282 & 1.79718 & 1.4872 & 1.26172 \\
$\begin{array}{c}\text { Valid N } \\
\text { (listwise) }\end{array}$ & 40 & & & & & & \\
\hline
\end{tabular}

P: pleasure-displeasure; A: arousal-non-arousal; D: dominance-submissiveness 
Table 6. Pearson Product-Moment Correlations for GSR and A

\begin{tabular}{ccccc}
\hline & A(arousal-nonarousal) & Rescue & Gates of Logic & Ballance \\
\hline \multirow{2}{*}{ GSR } & Pearson Correlation & $.242^{*}$ & $.407^{*}$ & $.436^{* *}$ \\
& Sig. (2-tailed) & .040 & .011 & .006 \\
$\mathrm{~N}$ & 40 & 40 & 40 \\
\hline
\end{tabular}

*. Correlation is significant at the 0.05 level (2-tailed).

**. Correlation is significant at the 0.01 level (2-tailed).

GSR is one of the most commonly used indicators to measure the emotional response. The change of emotional arousal leads to significant variation of GSR. GSR is considered as one of the objective index for emotion measure. Hence, correlation analysis was used to analyzing the arousal-non-arousal (A) of PAD Emotion Scales and GSR to find out that whether scales could consistently match with physiological data. The detailed results were displayed in Table 6.

The analyses demonstrated that GSR has a significant positive correlation with A of PAD Emotion Scales (see Table 6). In other words, GSR would consistently match with A, and the data of PAD Emotion Scales would reflect participants' emotional states objectively.

\subsection{Academic Emotions in the Educational Games}

We computed the participants' emotional states in each game with a combination of the PAD Emotion Scales and GSR, and divided specific emotional states into four dimensions of academic emotions according to Table 1. The descriptive statistics for academic emotions in the educational games demonstrated that while participants experienced mostly positive-low arousal emotion when they played "Rescue," they experienced mostly positive-high arousal emotion when they played "Gates of Logic" and "Ballance." On the whole, almost all of participants experienced positive academic emotions in the three educational games.

\subsection{Educational Games Design Features as Predictors of Academic Emotions}

Pearson Correlation analysis was conducted to examine the predictive relationships between the educational games design features of Learners' Psychological Pleasure Scale and academic emotions variables in three educational games. The detailed results were displayed in Table 7 to Table 10.

Regarding concentration, the analyses demonstrated that concentration was positively correlated with positive-high arousal emotions $(r=0.354, p=0.023<0.05)$, and negatively correlated with negative-low arousal emotions ( $r=-0.478, p=0.002<0.01)$ when the participants played the Gates of Logic. But, concentration was unrelated to academic emotions when they played the Rescue and Ballance. Because the pleasant degree of "concentration" of Gates of Logic was the lowest (see Table 4), it indicated that to a certain extent, "concentration" was conducive to make students experience more positive-high arousal emotions and less negative-low arousal emotions. But, when the students focused on the games too much, concentration was unrelated to academic emotions. Table 7 displays the Pearson productmoment correlations for "concentration" and academic emotions variables. 
Table 7. Pearson Product-Moment Correlations for "Concentration" and Academic Emotions

\begin{tabular}{|c|c|c|c|c|}
\hline & & $\begin{array}{l}\text { Game A } \\
\text { Rescue }\end{array}$ & $\begin{array}{c}\text { Game B Gates of } \\
\text { Logic }\end{array}$ & $\begin{array}{l}\text { Game C } \\
\text { Ballance }\end{array}$ \\
\hline \multirow[t]{3}{*}{$\begin{array}{l}\text { Positive-high } \\
\text { arousal }\end{array}$} & $\begin{array}{c}\text { Pearson } \\
\text { Correlation }\end{array}$ & -.002 & $.354^{*}$ & .018 \\
\hline & Sig. (2-tailed) & .992 & .023 & .911 \\
\hline & $\mathrm{N}$ & 40 & 40 & 40 \\
\hline \multirow[t]{3}{*}{$\begin{array}{l}\text { Positive-low } \\
\text { arousal }\end{array}$} & $\begin{array}{c}\text { Pearson } \\
\text { Correlation }\end{array}$ & .024 & -.025 & .036 \\
\hline & Sig. (2-tailed) & .880 & .875 & .822 \\
\hline & $\mathrm{N}$ & 40 & 40 & 40 \\
\hline \multirow[t]{3}{*}{$\begin{array}{l}\text { Negative-high } \\
\text { arousal }\end{array}$} & $\begin{array}{c}\text { Pearson } \\
\text { Correlation }\end{array}$ & -.062 & -.167 & -.065 \\
\hline & Sig. (2-tailed) & .700 & .298 & .684 \\
\hline & $\mathrm{N}$ & 41 & 41 & 41 \\
\hline \multirow[t]{3}{*}{$\begin{array}{l}\text { Negative-low } \\
\text { arousal }\end{array}$} & $\begin{array}{c}\text { Pearson } \\
\text { Correlation }\end{array}$ & .018 & $-.478^{* *}$ & -.005 \\
\hline & Sig. (2-tailed) & .912 & .002 & .973 \\
\hline & $\mathrm{N}$ & 40 & 40 & 40 \\
\hline
\end{tabular}

**. Correlation is significant at the 0.01 level (2-tailed).

*. Correlation is significant at the 0.05 level (2-tailed).

Regarding clear goals and feedback, the analyses demonstrated that they were both unrelated to academic emotions in the three educational games. It indicated that clear goals and feedback would not affect the students' academic emotions when they play educational games.

Regarding challenge, the analyses demonstrated that challenge was negatively correlated with negative-high arousal emotions $(r=-0.456, p=0.003<0.01)$ when the participants played the Gates of Logic, whereas it was unrelated to academic emotions when they played the Rescue and Ballance. The results showed that if the difficulty of the educational games was not to be adjusted in accordance with the students' challenge, they would tend to experience the negativehigh emotions. Table 8 displays the Pearson product-moment correlations for "challenge" and academic emotions variables. 
Table 8. Pearson Product-Moment Correlations for "Challenge" and Academic Emotions

\begin{tabular}{|c|c|c|c|c|}
\hline & & $\begin{array}{l}\text { Game A } \\
\text { Rescue }\end{array}$ & $\begin{array}{c}\text { Game B Gates of } \\
\text { Logic }\end{array}$ & $\begin{array}{l}\text { Game C } \\
\text { Ballance }\end{array}$ \\
\hline \multirow[t]{3}{*}{$\begin{array}{l}\text { Positive-high } \\
\text { arousal }\end{array}$} & $\begin{array}{c}\text { Pearson } \\
\text { Correlation }\end{array}$ & .138 & .230 & .124 \\
\hline & Sig. (2-tailed) & .389 & .147 & .439 \\
\hline & $\mathrm{N}$ & 40 & 40 & 40 \\
\hline \multirow[t]{3}{*}{$\begin{array}{l}\text { Positive-low } \\
\text { arousal }\end{array}$} & $\begin{array}{c}\text { Pearson } \\
\text { Correlation }\end{array}$ & .049 & .201 & .134 \\
\hline & Sig. (2-tailed) & .762 & .207 & .403 \\
\hline & $\mathrm{N}$ & 40 & 40 & 40 \\
\hline \multirow[t]{3}{*}{$\begin{array}{l}\text { Negative-high } \\
\text { arousal }\end{array}$} & $\begin{array}{c}\text { Pearson } \\
\text { Correlation }\end{array}$ & -.213 & $-.456 * *$ & -.207 \\
\hline & Sig. (2-tailed) & .181 & .003 & .194 \\
\hline & $\mathrm{N}$ & 40 & 40 & 40 \\
\hline \multirow[t]{3}{*}{$\begin{array}{l}\text { Negative-low } \\
\text { arousal }\end{array}$} & $\begin{array}{c}\text { Pearson } \\
\text { Correlation }\end{array}$ & -.235 & -.153 & -.173 \\
\hline & Sig. (2-tailed) & .139 & .341 & .278 \\
\hline & $\mathrm{N}$ & 40 & 40 & 40 \\
\hline
\end{tabular}

**. Correlation is significant at the 0.01 level (2-tailed).

*. Correlation is significant at the 0.05 level (2-tailed).

Regarding control, the analyses demonstrated that control was positively correlated with positive-high arousal emotions $(r=0.397, p=0.010<0.05)$, and negatively correlated with negative-high arousal emotions $(r=-0.553, p=0.000<0.01)$ when the participants played the Gates of Logic. But, control was unrelated to academic emotions when they played the Rescue and Ballance. On the other hand, because the pleasant degree of "control" of Gates of Logic was lowest (see
Table 4), it indicated that to a certain extent, the higher students felt the level of sense of control in educational games, the more they could experience positive-high arousal emotions, and the less they could experience negativehigh arousal motions. But, if it exceeded a certain level, the control would be unrelated to academic emotions. Thus, the educational games' design should make the students keep their control at the appropriate level. The detailed results were displayed in Table 9. 
Table 9. Pearson Product-Moment Correlations for "Control" and Academic Emotions

\begin{tabular}{|c|c|c|c|c|}
\hline & & $\begin{array}{l}\text { Game A } \\
\text { Rescue }\end{array}$ & $\begin{array}{c}\text { Game B Gates of } \\
\text { Logic }\end{array}$ & $\begin{array}{l}\text { Game C } \\
\text { Ballance }\end{array}$ \\
\hline \multirow[t]{3}{*}{$\begin{array}{l}\text { Positive-high } \\
\text { arousal }\end{array}$} & $\begin{array}{c}\text { Pearson } \\
\text { Correlation }\end{array}$ & -.036 & $.397^{*}$ & .150 \\
\hline & Sig. (2-tailed) & .822 & .010 & .349 \\
\hline & $\mathrm{N}$ & 40 & 40 & 40 \\
\hline \multirow[t]{3}{*}{$\begin{array}{l}\text { Positive-low } \\
\text { arousal }\end{array}$} & $\begin{array}{c}\text { Pearson } \\
\text { Correlation }\end{array}$ & .081 & .118 & -.084 \\
\hline & Sig. (2-tailed) & .617 & .461 & .600 \\
\hline & $\mathrm{N}$ & 40 & 40 & 40 \\
\hline \multirow[t]{3}{*}{$\begin{array}{l}\text { Negative- } \\
\text { high arousal }\end{array}$} & $\begin{array}{c}\text { Pearson } \\
\text { Correlation }\end{array}$ & .008 & $-.553^{* *}$ & -.240 \\
\hline & Sig. (2-tailed) & .959 & .000 & .131 \\
\hline & $\mathrm{N}$ & 40 & 40 & 40 \\
\hline \multirow[t]{3}{*}{$\begin{array}{l}\text { Negative- } \\
\text { low arousal }\end{array}$} & $\begin{array}{c}\text { Pearson } \\
\text { Correlation }\end{array}$ & -.153 & -.198 & .118 \\
\hline & Sig. (2-tailed) & .338 & .215 & .463 \\
\hline & $\mathrm{N}$ & 40 & 40 & 40 \\
\hline
\end{tabular}

**. Correlation is significant at the 0.01 level (2-tailed).

*. Correlation is significant at the 0.05 level (2-tailed).

Regarding immersion, the analyses demonstrated that immersion had a negative correlation with negative-low arousal emotions $(r=-0.372, p=0.017<0.05)$ when the participants played the Gates of Logic; immersion was significant negative predictors of negative-high arousal emotions $(r=-0.326$, $p=0.038<0.05)$ in Ballance. But, immersion was unrelated to academic emotions when they played the Rescue. On the other hand, because the pleasant degree of "immersion" of Gates of Logic was lowest, which was highest in Ballance (see Table4), it indicated that when students' immersion was very high or very low, the higher students felt the level of immersion in educational games, the less they could experience negative emotions. Also, high immersion was negative predictors of negative-high arousal emotions; low immersion was negatively correlated with negative-low arousal emotions. But, with the continuous improvement of immersion, there would be a buffer. That is when immersion is in the general level, it tends to make students experience negative emotions. The detailed results were displayed in Table 10. 
Table 10. Pearson Product-Moment Correlations for "Immersion" and Academic Emotions

\begin{tabular}{lcccc}
\hline & & Game A & Game B Gates of & Logic \\
Positive-high & Pearson Correlation & -.104 & .161 & Game C \\
arousal & Sig. (2-tailed) & .518 & .316 & .288 \\
& $\mathrm{~N}$ & 40 & 40 & .068 \\
& & & & 40 \\
Positive-low & Pearson Correlation & .142 & .088 & \\
arousal & Sig. (2-tailed) & .376 & .586 & -.080 \\
& $\mathrm{~N}$ & 40 & 40 & .618 \\
& & & & 40 \\
Negative-high & Pearson Correlation & .035 & -.104 & $-.326^{*}$ \\
arousal & Sig. (2-tailed) & .828 & .519 & .038 \\
& $\mathrm{~N}$ & 40 & 40 & 40 \\
& & & & \\
Negative-low & Pearson Correlation & -.187 & $-.372^{*}$ & -.049 \\
arousal & Sig. (2-tailed) & .241 & .017 & .762 \\
& $\mathrm{~N}$ & 40 & 40 & 40 \\
\hline
\end{tabular}

**. Correlation is significant at the 0.01 level (2-tailed).

*. Correlation is significant at the 0.05 level (2-tailed).

\section{Discussion}

\subsection{Participants Experience More Positive Academic Emotions in Educational Games}

The preliminary findings of Pearson Product-Moment Correlations analyses for GSR and A of PAD Emotion Scales corroborated that GSR had a significant positive correlation with A of PAD Emotion Scales; in other words, GSR could consistently match with A.

Descriptive statistics for academic emotions demonstrated that almost all of participants experienced positive academic emotions in the three different kinds of educational games. This meant that educational games indeed stimulated students' positive emotional experiences.

\subsection{The Relationship between Educational Games Design Features and Academic Emotions}

The primary results revealed clear links between educational games' design features and participants' academic emotions in three educational games. According to the analysis of Pearson Product-Moment correlations for design features and academic emotions, we can safely come to the conclusions as follows.

In accordance with Hypothesis 1, concentration and control positively predicted positive-high arousal emotions. The others design features were unrelated to positive emotions.

In line with Hypothesis 2, concentration was negatively related to negative-low arousal emotions. Challenge and control negatively predicted negative-high arousal emotions. Immersion was negatively related to negative- 
high arousal emotions and negative-low arousal emotions. In other words, immersion negatively predicted negative emotions.

Comprehensive consideration of the difference of pleasant degree of design features among the three educational games, we could draw inferences as follows. First, students may experience more positivehigh arousal emotions and less negative-low arousal emotions when their concentration at an appropriate level. If the students focus on the games too much, the concentration cannot rouse students' positive academic emotions. Second, the students' academic emotions would be affected by challenge, thus the difficulty of the educational games should be adjusted in accordance with the students' challenge to help them experience the position emotions. Third, the educational games' design should make the students keep their control at the appropriate level. Because if it exceeds a certain level, does not allow students will not experience the positive emotions. Fourth, when students' immersion is very high or very low, the students will experience less negative emotions. The high immersion was negative predictors of negative-high arousal emotions; low immersion was negatively correlated with negative-low arousal emotions. However, when immersion was in the middle level, it was not conducive to experience less negative emotions because the level was unrelated to academic emotions. Fifth, clear goals and feedback were both unrelated to academic emotions in the three educational games. That is, they would not affect the students' academic emotions when they play educational games.

In sum, the hypotheses of our study were verified. Concentration, challenge, control, and immersion do predict students' academic emotions in varying degrees. First, regarding positive-high arousal emotions, concentration and control both positively predicted positive-high arousal emotions. The predictive power of control $(r=0.397)$ was stronger than concentration $(r=0.354)$. Second, regarding positive-low arousal emotions, the six educational games' design features were all unrelated to academic emotions in the three educational games. Third, regarding negativehigh arousal emotions, control, challenge, and immersion were negatively related to negative-high arousal emotions. Moreover, the relationship between control and negativehigh arousal emotions $(r=-0.553)$ was most significant. The predictive power of challenge $(r=-0.456)$ was stronger than immersion $(r=-0.326)$, which is referred to high immersion. Fourth, regarding negative-low arousal emotions, concentration and immersion had negative correlation with negative-low arousal emotions. The relationship between concentration and negative-high arousal emotions $(r=-0.478)$ was more significant than immersion $(r=-0.372)$, which is referred to low immersion. Thus, when we design educational games, programmers should place a priority on designing control.

\subsection{The Limitations in This Study}

First, we acknowledge the limitation that causality cannot be claimed based on correlation patterns among the variables alone. Although the analyses imply that educational games' design features significantly predicted the academic emotional outcomes, it is also possible that the other variables may arouse the academic emotions in above educational games. Second, we conducted a cross-sectional study using data at one point of time rather than a longitudinal study due to the availability of the data. As such, we cannot draw conclusions regarding the possible changing relationships between different educational games involvement and weights of design features. Third, despite our efforts to capture the academic emotions in educational games, we did not analyze other 
physiological data besides GSR. All of these other physiological data should be taken into account as well, which can also be used to measure human emotion such as EEG, Temp, BVP, RSP and HRV.

Consequently, future research need to give due weight to the four design elements designed in the educational games. Other factors should be considered as well such as characteristics of the players. In other words, the correlation patterns among the characteristics of the players, educational game design features, and academic emotions should be further explored. For example, as a lot of studies have shown, students' achievement goals could influence their academic emotions in traditional classroom environments (Daniels, Stupnisky, \& Pekrun, 2009). Researchers need to indicate whether the students' achievement goals influence their academic emotions in educational games, and explore the correlation patterns among the achievement goals, educational game design features, and academic emotions.

\section{References}

Bailey, R., \& Wise, K. (2009). How avatar customizability affects children's arousal and subjective presence during Junk Food-Sponsored online video games. CyberPsychology\& Behavior, 12(3), 277-283.

Bruckman, A. (1998). Community support for constructionist learning. Computer Supported Cooperative Work, 7, 47-86.

Buckingham, D., \& Scanlon, M. (2000). That is edutainment: Media, pedagogy and the market place. Proceedings from the International Forum of Researchers on Young People and the Media. Sydney, Australia.

Cai, J. (2010). The research of emotion recognition based galvanic skin response signal. Chongqing, China: Southwest University. Retrieved from CNKI.

Chen, Y. S.(2010). Emotion management and highly interactivity video games: Examining emotion change in relation to arousal, involvement, and enjoyment. USA: The Florida State University. Retrieved from ProQuest Digital Dissertations.

Daniels, L. M., Stupnisky, R. H., Pekrun, R., Haynes, T. L., Perry, R. P., \& Newall, N. E. (2009). A longitudinal analysis of achievement goals: From affective antecedents to emotional effects and achievement outcomes. American Psychological Association, 101(4), 948-963.

Dede, C., Ketelhut, D., \& Ruess, K.(2002). Motivation, usability and learning outcomes in a prototype museum-based muti-user virtutal environment. ICLS, Scattle, Washington.

Diener, H. (2006). Serious games--Games for interactive simulation and training. Proceedings of Edutainment 2006: International Conference of E-Learning and Games. Hangzhou, China.

Dong, Y., \& Yu, G. L.(2007).The development and application of an academic emotions questionnaire. ActaPsychologicaSinica, 39(5), 852-860.

Egenfeldt-Nielsen, S. (2005). Beyond edutainment: Exploring the educational potential of computer games. Denmark: IT University of Copenhagen, Department of Innovation.

Goleman, D. (1995). Emotional Intelligence. New York, USA: Bantam Books.

John-Steiner, V. (2000). Creative Collaborations. Britain: Oxford University Press.

Jong, M., Shang, J.J., Lee, F.L., Lee, J.M.H., \& Law, H.Y. (2006). Learning online: A comparative study of a situated game-based approach and a traditional web-based approach. Proceedings of Edutainment 2006: International Conference of $E$ -Learning and Games. Hangzhou, China. 
Kiili, K. (2005). Educational game design: Experiential gaming model revised. Tampereenteknillinenyliopisto, Porinyksikkö, Pori 2005.

Lee, H.M.J., Lee, F.L., \& Lau, T.S. (2006). Folklore-based learning on the web-Pedagogy, case study and evaluation. Journal of Educational Computing Research, 34(1), 1-27.

Li, X. M., Zhou, H. T., Song, S. Z., Ran, T., \& Fu, X. L. (2005). The reliability and validity of the Chinese version of abbreviated PAD emotion scales. LNCS 3784, 513-518.

Liu, H. J. (2003). The study of relation between achievement goal orientations, working memory span and controlled retrieval. Beijing, China: Capital Normal University. Retrieved from CNKI.

Mehrabian, A., \& Russell, J. A. (1974). An approach to environmental psychology. Cambridge, MA.: MIT Press.

Mehrabian, A. (1995). Framework for a comprehensive description and measurement of emotional states. Genet Soc Gen PsycholMonogr, 121, 339 - 361.

Nummenmaa, M., \& Nummenmaa L. (2008) University students' emotions, interest and activities in a web-based learning environment[J]. British Journal of Educational Psychology, 78: 163-178.

Pekrun, R., Gortz, T., \& Titz, W. (2002). Academic emotion in students' selfregulated learning and achievement: A program of qualitative and quantitative research. Educational Psychologist, 37(2), 91-105.

Prensky, M. (2000). Digital game-Based learning. New York, USA: McGraw Hill.

Ravaja, N., \& aari, T. (2006). Spatial presence and emotions during video game playing: Does it matter with whom you play? Massachusetts Institute of Technology, 15(4), 381-392.
Su, R.Z. (2007). The study on design and evaluation indicators of digital educational games. Taiwan, China: National Chengchi University. Retrieved from ProQuest Digital Dissertations.

Sweetser, P., \& Wyeth, P.(2005). GameFlow: A model for evaluating player enjoyment in games. Computers in Entertainment, 3(3), 1-24.

Wang, W. (2010).Grading and classification of electronic games in educational perspective. Beijing, China: Science Press.

Weinstein, A. M. (2010). Computer and video game addiction-A comparison between game users and non-game users. The American Journal of Drug and Alcohol Abuse, 36(5), 268-276.

Zhou, Y., \& Zhang, C. (2010). The factors of computer game addiction and the development of educational games. E-Education Research, 7, 44-47.

\section{Acknowledgement}

This study was supported by the Ministry of Education of the People's Republic of China (DCA090319), Education Department, Jiangsu Province (09SJB880038).

\section{Contact the Authors}

Yue-Xiang Zhang

Wuxi No.1 Senior High School

Email: yuexiangz99@126.com

\section{Jian-Sheng $\mathrm{Li}$}

Nanjing Normal University

Email: jianshengli333@163.com

\section{Yi Li}

Nanjing Normal University

Email: yilisd@163.com 